Canadian

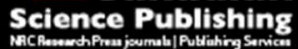

Canadian Journal of Physiology and Pharmacology Revue canadienne de physiologie et pharmacologie

\title{
Effect of valsartan on cardiac senescence and apoptosis in a rat model of cardiotoxicity
}

\begin{tabular}{|r|l|}
\hline Journal: & Canadian Journal of Physiology and Pharmacology \\
\hline Manuscript ID & cjpp-2015-0461.R1 \\
\hline Manuscript Type: & Article \\
\hline Date Submitted by the Author: & 08-Dec-2015 \\
\hline Complete List of Authors: & $\begin{array}{l}\text { Sakr, Hussein; KIng Khalid University, college of Medicine, } \\
\text { Abbas, Amr; Faculty of Medicine, Physiology } \\
\text { Elsamanoudy, Ayman; Faculty of Medicine, Mansoura University, Medical } \\
\text { biochemistry }\end{array}$ \\
\hline Keyword: & Doxorubicin, valsartan, oxidative stress, apoptosis, senescence \\
\hline \multicolumn{2}{|c}{} \\
\hline
\end{tabular}




\title{
Effect of valsartan on cardiac senescence and apoptosis in a rat model of cardiotoxicity
}

\author{
Hussein F. Sakr ${ }^{1}$, Amr M. Abbas ${ }^{1}$, Ayman Z. Elsamanoudy ${ }^{2}$ \\ ${ }^{1}$ Medical Physiology Department, Faculty of Medicine, Mansoura University, Mansoura, Egypt \\ ${ }^{2}$ Medical Biochemistry and Molecular Biology Department, Faculty of Medicine, Mansoura University, Mansoura, \\ Egypt
}

Running title: valsartan and cardiotoxicity

\section{Dr. Hussein F. Sakr}

Medical Physiology department,

Faculty of Medicine,

Mansoura University, Egypt.

PO Box: 35516, Mansoura, Egypt

E-mail: sakr_doctor@yahoo.com

Telephone: Office: 0020502305557

Mobile: 00201127720093 


\begin{abstract}
The clinical application of doxorubicin is limited by its cardiotoxicity. The present study investigated the effect of valsartan on doxorubicin-induced cardiotoxicity in rats. Rats were divided into 6 groups; control, control+valsartan (10 mg/kg, for 14 days, orally), and doxorubicin-treated $(2.5 \mathrm{mg} / \mathrm{kg}, 3$ times/week for 2 weeks, intraperitoneally), valsartan then doxorubicin; valsartan+doxorubicin and doxorubicin then valsartan. ECG, isolated heart, lipid peroxidation (TBARS), total anti-oxidant capacity (TAC), and Bax, Bcl-2 and senescence marker protein 30 (SMP30) gene expression were measured in cardiac tissue. Blood samples were collected to measure lactate dehydrogenase (LDH) and creatine kinase MB (CK-MB). Doxorubicin significantly increased LDH, CK-MB, TBARS, heart rate (HR), Bax gene expression and $-\mathrm{d} P / \mathrm{d} t$ max and decreased TAC, Bcl-2 and SMP30 gene expression, left ventricular developed pressure (LVDP) and $+\mathrm{d} P / \mathrm{d} t$ max. Also, doxorubicin lengthened ST, QT and QTc intervals. Concurrent or post but not pre treatment of doxorubicin-treated rats with valsartan reduced LDH, CK-MB, TBARS, HR, Bax gene expression, $-\mathrm{d} P / \mathrm{d} t$ max, and ST, QT and QTc intervals and increased TAC, Bcl-2 and SMP30 gene expression, LVDP and $+\mathrm{d} P / \mathrm{d} t$ max. Therefore, we conclude that concurrent or post but not pre treatment of doxorubicin-induced rats with valsartan attenuated doxorubicin-induced cardiotoxicity through inhibiting oxidative stress, apoptosis and senescence.
\end{abstract}

Key wards: Doxorubicin, valsartan, oxidative stress, apoptosis, senescence 


\section{Introduction}

Doxorubicin (DOX), an anthracycline antibiotic, is widely used in the treatment of a variety of solid and hematological malignancies. However, the clinical application of this chemotherapeutic drug is limited by its severely cumulative dose-dependent cardiotoxicity that can cause cardiomyopathy and heart failure (Ferreira et al. 2008). The exact pathogenesis of DOX-induced cardiotoxicity is not fully understood, but different mechanisms have been proposed, including oxidative stress, intracellular calcium overload, myofibrillar degeneration, cytokine release, and induction of cardiomyocyte apoptosis (Volkova and Russell 2011). Among these mechanisms, oxidative stress and apoptosis appear to be the main triggers of this drug-induced cardiotoxicity (Octavia et al. 2012). Moreover, it has recently been suggested that senescence may be another mechanism of cardiotoxicity induced by DOX (Spallarossa et al. 2009). Cellular senescence is a fundamental cellular program which is characterized by a series of morphological and physiological changes including irreversible block of proliferation. In addition, it contributes to the physiology of living tissues, the aging process, and age-related diseases as cancer, diabetes, osteoporosis, and cardiovascular and neurodegenerative diseases (Rattan 2012). Therefore, it is necessary to investigate cardioprotective adjuvants to minimize the cardiotoxicity of DOX.

Previous studies have have suggested that the renin-angiotensin system (RAS) plays an important role in the development of cardiac hypertrophy, failure and reperfusion injury (Zablocki and Sadoshima 2013). Suppression of the RAS ameliorates the remodeling process of heart and prolongs long-term survival in animal models and humans with cardiac hypertrophy, failure and reperfusion injury (Iqbal et al. 2008). Interestingly, in rats that had undergone short- or long-term administration of DOX, co-administration of angiotensin-converting enzyme (ACE) inhibitors is reported to almost completely prevent the decline in cardiac function as well as the increase in left ventricular weight induced by DOX (Vaynblat et al. 2002). Furthermore, recent evidence has demonstrated that DOX cannot induce cardiac injury in angiotensin II type I (AT1) receptor gene knockout mice, indicating a key role of angiotensin II in the pathogenesis of DOX-induced cardiotoxicity (Toko et al. 2002).

Valsartan is a drug that selectively inhibits AT1 receptor. This drug was developed following the ACE inhibitors, as an option to provide more specific effects on the RAS. Valsartan interacts with the angiotensin receptor thereby selectively inhibiting its physiological actions (Burnier and Brunner 2000). Several studies had been published for the effect of valsartan and other angiotensin II receptor blocker (ARBs) to prevent DOX-induced cardiotoxicity in different animal models and human. Iqbal et al. (2008) suggested that telmisartan treatment 
provides a significant protective effect against acute DOX-induced cardiotoxicity in rats. In addition, Akolkar et al. (2015) reported that administration of valsartan for 13 weeks ameliorated the DOX-induced cardiotoxicity in mice. By application of these basic scientific findings to the clinical field, a number of clinical studies have evaluated the potential cardioprotective role of ARBs in the clinical setting of chemotherapy-mediated cardiotoxicity. In a study by Nakamae et al. (2005), they observed that in patients treated with valsartan together with cyclophosphamide, doxorubicin, vincristin, and prednisone (CHOP), all the changes in cardiac markers, except for the elevation in serum ANP, were prevented, indicating that valsartan has a strong effect in preventing acute CHOP-induced cardiotoxicity. Moreover, in a small prospective study including 49 patients with various cancers responsive to an anthracycline based chemotherapy regimen, Dessì et al. (2011) demonstrated that ARB was able to reverse acute myocardial dysfunction up to 12 months of follow-up. Also, in a recent meta-analysis, the prophylactic administration of ACE inhibitor or ARB in patients receiving an anthracycline based regimen was associated with a relative risk of 0.11 for the development of cardiotoxicity compared to placebo (Kalam and Marwick 2013).

Thus, we hypothesized that valsartan could attenuate the DOX-induced cardiotoxicity in rats. To test our hypothesis, the present study was designed to investigate the possible protective effect of valsartan on DOX-induced cardiotoxicity in rats using biochemical markers of oxidative stress, senescence marker protein 30 (SMP30) as a marker of ventricular cardiomyocyte senescence and Bax and Bcl-2 gene expression to assess apoptosis.

\section{Materials and methods:}

\section{Experimental animals:}

One hundred and fifty six male Sprague Dawley rats, 7 weeks of age, weighing 180-220 g were purchased from the Vaccine and Immunization Authority (Helwan, Cairo, Egypt) and housed (Animal House, Medical Physiology Department, Faculty of Medicine, Mansoura University, Egypt) under controlled conditions (temperature of $23 \pm 1{ }^{\circ} \mathrm{C}$, and a $12 \mathrm{~h}$ light: $12 \mathrm{~h}$ dark cycle). The animals were allowed free access to food and tap water. Experiments were performed according to the Guide for the Care and Use of Laboratory Animals published by the US National Institutes of Health (NIH publication No. 85-23, revised 1996). All experimental procedures in this study were approved by the Medical Research Ethics Committee of Mansoura University, Egypt.

\section{Experimental design}

After acclimatization, the rats were assigned randomly to six groups of 26 rats each. Group I (normal control group) administered normal saline intraperitoneally and served as the control group. Group II (Valsartan 
treated normal group) administered valsartan (10 mg/kg/day) (Khan and Imig 2011) for 14 days by oral gavage and served as the valsartan group. Group III (DOX treated group) administered a cumulative dose of DOX (15mg/ $\mathrm{kg})$ in six equal intraperitoneal (i.p.) injections ( $2.5 \mathrm{mg} / \mathrm{kg}, 3$ times a week for 2 weeks) (Siveski-Iliskovic et al. 1994) and served as the DOX group. Group IV (Valsartan pretreated group) included rats that were pre-treated with a daily dose of valsartan $(10 \mathrm{mg} / \mathrm{kg})$ orally by gavage for 14 days then treated with a cumulative dose of DOX, as previously mentioned, for the next 14 days. Group V included rats that were administered a combined dose of valsartan and DOX in the same route and doses, as previously mentioned, over a period of 14 days. Group VI (Valsartan post-treated group) included rats that were administered a cumulative dose of DOX, as previously mentioned, for the first 14 days then treated with a daily dose of valsartan $(10 \mathrm{mg} / \mathrm{kg})$ orally by gavage for the next 14 days.

At the end of the treatment, all rats were fasted overnight, electrocardiograph (ECG) was recorded, and then blood samples were collected. Then, 10 rats from each group were used in the experimental isolated Langendorff-perfused heart procedure. Then hearts from another 10 rats from each group were removed and used for quantitative real time RT-PCR of SMP30, Bax and Bcl-2 and preparation of cardiac homogenate for determination of oxidative stress markers. The hearts of the remaining 6 rats were used for histopathological examination.

\section{Technique of ECG recording}

At the end of the treatment, all rats were fasted overnight but had free access to water. All rats were placed in the supine position on a board, under the effect of light ether anesthesia, and ECG was recorded using computerized MP36 data acquisition system Biopac Student lab (BIOPAC Systems Inc, CA, USA). Touch electrodes were attached to the skin of the animals at position II for ECG recording. The recorded ECG was used to measure ST, QT and QTc intervals; QRS complex; and heart rate (HR). Corrected QT (QTc) was calculated from Bazett's formula.

\section{Collection of blood sampling}

Directly after ECG recording, blood samples were collected from all rat groups from the rat's eye orbital plexus by pasture pipette in a plain tube which was then allowed to clot at room temperature, and serum was separated by centrifuging the tube at $4000 \mathrm{rpm}$ for $10 \mathrm{~min}$. Then, serum was stored at $-20^{\circ} \mathrm{C}$ until further biochemical analysis for determination of lactate dehydrogenase (LDH) and creatine kinase (CK-MB) levels using special ELISA kits according to the manufacturer's instructions. 


\section{Isolated Langendorff-perfused heart}

After blood collection, 10 rats of each group were used in this experimental procedure. The rats were anesthetized with an intraperitoneal injection of sodium pentobarbital (60 mg/kg, i.p.; Abbott Laboratory, Chicago, IL, USA) and given heparin (500 IU, i.v.). The hearts were rapidly excised and perfused through aorta according to the Langendorff's method at a perfusion pressure of $75 \mathrm{mmHg}$. The perfusate was a Krebs-Henseleit solution containing NaCl 118 mmol/l, NaHCO3 25 mmol/l, KCl 4.75 mmol/l, KH2PO4 1.18 mmol/l, MgSO4 1.17 mmol/l, $\mathrm{CaCl} 21.25 \mathrm{mmol} / \mathrm{l}$, glucose $10 \mathrm{mmol} / \mathrm{l}\left(\mathrm{pH} 7.4,37^{\circ} \mathrm{C}\right)$, and was bubbled constantly with $95 \% \mathrm{O}_{2}$ and $5 \% \mathrm{CO}_{2}$, as previously reported and the temperature of the heart was maintained at $37^{\circ} \mathrm{C}$. After $15-20$ minutes of equilibration, a water-filled balloon attached to a rigid polyethylene tube was introduced into the left ventricle through the mitral valve. The whole setting was connected to a pressure transducer (MLT0670, AD Instruments, New South Wales, Australia) that is connected to a bridge amplifier (FE117 BP Amp, AD Instruments, New South Wales, Australia). The following parameters were recorded: the left ventricular developed pressure (LVDP) and the peaks of the positive and negative pressure derivatives (respectively, $\mathrm{dP} / \mathrm{dtmax}$ and $-\mathrm{dP} / \mathrm{dtmax}$ ) by the use of PowerLab data acquisition system (AD Instruments, Australia) (Eleawa et al. 2013).

\section{Assay of thiobarbituric acid reactive substances (TBARS) and total anti-oxidant capacity (TAC)}

Hearts were remove from another 10 rats from each group and transferred into Petri dish. Then adipose tissues and blood vessels were removed. Subsequently, hearts were washed with ice-cold isotonic saline, blotted individually on ash free filter paper and cut into many pieces.

About $0.2-0.3 \mathrm{~g}$ from each heart was homogenized separately in $0.1 \mathrm{~mol}$ Tris-HCl buffer, $\mathrm{pH} 7.4$ using a using a Potter-Elvejhem homogenizer at $4{ }^{\circ} \mathrm{C}$ with a diluting factor of 4 . The crude tissue homogenate was then centrifuged at a speed of $9000 \mathrm{rpm}$ for $15 \mathrm{~min}$ in a cold centrifuge, and the supernatant was collected and stored at $20{ }^{\circ} \mathrm{C}$ until analysis for measuring the levels of malondialdehyde using TBARS method and TAC.

Lipid peroxidation in the cardiac tissue homogenates was assessed with the TBARS assay method as previously described (Yoshioka et al. 1979). The results were expressed as nmol/g tissue. Moreover, TAC was measured according to the method of Katalinic et al. (2005). The results are expressed as Trolox equivalents per gram wet tissue weight.

Quantitative Real-Time PCR (qPCR) for determining the levels of gene expression: 
Total RNA was isolated from 50 to $100 \mathrm{mg}$ of left ventricle of rats' heart (from 10 rats) after shock freeze with liquid nitrogen using Tri-Fast TM reagent (PeqLab. Biotechnologie GmbH, Carl-Thiersch St. 2B 91052 Erlongen, Germany, Cat. No. 30-2010), triazol and chloroform. The purity of RNA was determined by gel electrophoresis using formaldehyde agarose gel electrophoresis and ethidium bromide staining to show two sharp bands representing $28 \mathrm{~S}$ and $18 \mathrm{~S}$ ribosomal RNA.

The concentration and purity of the total RNA samples was checked by determining the absorbance at 230 , 260 and $280 \mathrm{~nm}$ in a spectrophotometer (Jenway, Genova Model, UK). The benchmark used to evaluate these ratios (A260/ A280 and A260/A230) was greater than or equal to 1.8.

Total RNA (1 mg) was used for cDNA synthesis reactions using QIAGEN Long Range 2 Step RT-PCR Kit (100 reactions); (Germany-cat. no. 205922): $20 \mu$ reaction mix was prepared by addition of $2 \mu 1$ of template extracted RNA from sperm pellet and 9.8 $\mu$ DEPC treated water to Reverse-Transcription Master Mix that contains $4 \mu 1$ Long

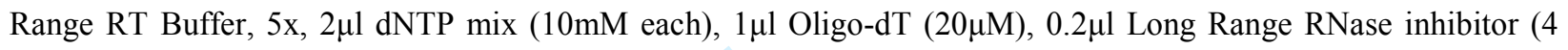
$\mathrm{U} / \mu \mathrm{l})$ and $1 \mu \mathrm{l}$ Long Range Reverse Transcriptase. The protocol of reverse transcriptase and cDNA synthesis was carried out according to the manufacturer's instructions by mixing the master mix thoroughly and carefully by vortexing for 5 seconds, incubating for $50 \mathrm{~min}$ at $42^{\circ} \mathrm{C}$ then, inactivating the enzyme by heating at $85^{\circ} \mathrm{C}$ for $15 \mathrm{~min}$. The synthesized cDNA is stored at $-80{ }^{\circ} \mathrm{C}$ until utilized for quantitative real time RT-PCR for SMP30, Bax and Bcl2 against the house keeping control gene, $\beta$-actin.

The relative gene expression of the studied genes were quantified using real-time polymerase chain reaction (qRT-PCR) (7500 Fast Real-Time PCR System, Applied Biosystems, Foster City, CA, USA). Real-time PCR was carried out using the using SybrGreen reagent [SYBR ${ }^{\circ}$ Green PCR Master Mix (Applied Biosystem, USA, Cat. No. 4344463].

The sequences of the primers used were designed by other authors: SMP30, forward: 5'AGGCATCAAAGTGTCTGCTGTTT3'; reverse: 5'GACTGTCGAAGTGCCACTGAACT3' (Huang et al. 2001). Bax, forward: 5'CCAGGACGCATCCACCAAGAAGC3'; reverse, 5'TGCCACACGGAAGAAGACCTCTCG3' (136 bp product size) (Li et al. 2011). Bcl-2, forward: 5'GGATGACTTCTCTCGTCGCTACCGT3'; reverse, 5'ATCCCTGAAGAGTTCCTCCACCAC3' (118 bp product size) (Li et al. 2011). $\beta$-actin, forward: 5'GTCGTACCACTGGCATTGTG3'; reverse: 5'CTCTCAGCTGTGGTGGTGAA3' (Wang et al. 2008). 
Reactions were performed in duplicates; Reaction mix for SMP30 was performed $25 \mu \mathrm{L}$ contains forward and reverse primers (10 pmol), $12.5 \mu \mathrm{L}$ Sybr ${ }^{\circledR}$ Green PCR Master Mix reaction buffer (Applied Biosystems) and $2 \mu 1$ cDNA. Quantitative real time PCR was performed using a 7500 Fast Real-Time PCR System (Applied Biosystems, Foster City, CA, USA) for SMP30: 40 cycles at $95^{\circ} \mathrm{C}$ for $20 \mathrm{~s}, 60^{\circ} \mathrm{C}$ for $3 \mathrm{~s}$ and $60{ }^{\circ} \mathrm{C}$ for $20 \mathrm{~s}$ (Arruda et al. 2013). For Bax and Bcl-2, quantitative real time PCR was performed according to the method described by Li et al. (2011) using the following mix and program:The reactions were performed in a $20-1 \mu \mathrm{L}$ volume mix containing $10 \mu \mathrm{L}$ SYBR Green I mixture, $1 \mu \mathrm{L}$ primers, $1 \mu \mathrm{L}$ cDNA, and $1 \mu \mathrm{L}$ sterile, distilled-deionized water. Cycling conditions were as follows: 3 min at $95^{\circ} \mathrm{C}, 44$ cycles of $15 \mathrm{~s}$ at $95{ }^{\circ} \mathrm{C}, 20 \mathrm{~s}$ at $60^{\circ} \mathrm{C}$, and $15 \mathrm{~s}$ at $72{ }^{\circ} \mathrm{C}$.

The amplification specificity of each amplified product was verified using a melting curve. The efficiency of the qPCR amplification reactions was evaluated by running standard curves for each amplicon using different template dilutions of cDNA $(1: 10,1: 100,1: 250,1: 500,1: 1000,1: 2000$ and 1:10000). The expression of all genes was normalized to the expression of the housekeeping gene $\beta$-actin and the reactions were run in duplicate.

Melting curve analysis was used to examine the specificity of the products generated for each primer set. The comparative $\mathrm{C}_{\mathrm{T}}$ method was used to quantitate the abundance of target gene mRNA and is given by $2^{-\Delta \Delta C}{ }_{\mathrm{T}}$.

The relative gene expression levels were calculated using method arithmetic formulae. The controlnontreated samples were used as calibrators. The amount of target, normalized to an endogenous housekeeping gene ( $\beta$-actin) and relative to the calibrator, is then given by $\Delta \Delta C_{\mathrm{T}}$, where $\Delta \Delta C_{\mathrm{T}}=\Delta C_{\mathrm{T}}$ (sample) $-\Delta C_{\mathrm{T}}$ (calibrator), and $\Delta C_{\mathrm{T}}$ is the $C_{\mathrm{T}}$ of the target gene subtracted from the $C_{\mathrm{T}}$ of the housekeeping gene. For the untreated-control sample, $\Delta \Delta C_{\mathrm{T}}$ equals zero, and $2^{0}$ equals one, so that the fold change in gene expression relative to the untreated-control equals one, by definition. For the treated samples (studied group samples), evaluation of $\Delta \Delta C_{\mathrm{T}}$ indicates the fold change in gene expression relative to the untreated-control.

\section{Histopathological Examination}

The hearts of the remaining 6 rats from each group were fixed in $10 \%$ formol saline for one day, and then washed with water. Ascending serial dilutions of ethyl alcohol were used for dehydration. Samples were cleared in xylene, and then embedded in paraffin at 56 degree in hot oven for 24 hours. Paraffin blocks were prepared and cut at 4-6 microns thickness. Sections are mounted on glass slides, deparaffinized and stained by hematoxylin and eosin stains for histological examinations through the light microscope.

\section{Statistical analysis}


The data were expressed as mean \pm standard deviation (SD). Data were processed and analyzed using the SPSS version 10.0 (SPSS, Inc., Chicago, IL, USA). One-way analysis of variance (ANOVA) was done followed by Tukey's post hoc test. Pearson's correlation statistical analysis was done for detection of a probable significance between two different parameters. Results were considered significant if $p \leq 0.05$.

\section{Results}

\section{Effects of valsartan and DOX treatment on contractile variables (LVDP, dP/dtmax and -dP/dtmax):}

Table 1 showed that the valsartan treatment of normal rats produced non-significant $(p>0.05)$ change in the different contractile variables (LVDP, $+\mathrm{d} P / \mathrm{d} t$ max and $-\mathrm{d} P / \mathrm{d} t \max$ ) versus the control group. DOX treatment alone or after valsartan significantly $(p<0.05)$ reduced LVDP and $+\mathrm{d} P / \mathrm{d} t$ max and increased $-\mathrm{d} P / \mathrm{d} t$ max as compared with both control groups (control and Control + Valsartan). In addition, valsartan treatment with and after DOX significantly $(p<0.05)$ increased the LVDP and $+\mathrm{d} P / \mathrm{d} t$ max and decreased $-\mathrm{d} P / \mathrm{d} t$ max as compared with DOX induced rats either untreated or valsartan pretreated.

\section{Effects of valsartan and DOX treatment on heart rate and different ECG parameters:}

Table 2 showed that valsartan treatment in the control rats insignificantly $(p>0.05)$ changed ST, QT and QTc intervals as well as QRS and heart rate. DOX treated rats alone or after valsartan showed a significant increase in heart rate, prolongation of ST, QT and QTc intervals with non significant change in QRS duration, as compared with the control rats $(p<0.05)$. Addition of valsartan with and after DOX significantly $(p<0.05)$ reduced the heart rate, shortens ST, QT and QTc intervals with non significant change in QRS duration as compared with either DOX alone or valsartan pretreated group.

\section{Effects of valsartan and DOX treatment on cardiac marker enzymes:}

Cardiac markers enzymes (LDH and CK-MB) are shown in Table 3. Treatment of control rats with valsartan caused no change $(p>0.05)$ in cardiac markers enzymes (LDH and CK-MB). DOX caused a significant $(p<0.05)$ increase in cardiac markers enzymes (LDH and CK-MB) when compared with control group. While concurrent or post treatment of DOX-induced rats with valsartan caused a significant $(p<0.05)$ decrease in cardiac markers enzymes (LDH and CK-MB), pretreatment had no effect.

\section{Effects of valsartan and DOX treatment on cardiac TBARS and TAC:}

Figure 1 showed that rats treated with DOX had a significant increase in TBARS $(p<0.05)$ as compared with control rats. While addition of valsartan with or after DOX significantly $(p<0.05)$ decreased TBARS $(p<0.05)$ 
as compared with DOX treated rats, administration of valsartan before DOX produced insignificant $(p>0.05)$ change. However, the level of TBARS in rats treated with valsartan with or after DOX remain significantly higher than the control groups $(p<0.05)$ (Figure 1).

Figure 2 showed that valsartan treatment in control group produced insignificant increase $(p>0.05)$ in total anti-oxidants as compared with the control rats. Rats received DOX alone or after valsartan showed a significant decrease $(p<0.05)$ in total anti-oxidants versus the control groups (control rats and control treated with valsartan). Addition of valsartan with and after DOX significantly $(p<0.05)$ increased total anti-oxidants as compared with DOX treated rats but still significantly $(p<0.05)$ lower than the control groups (Figure 2 ).

\section{Effects of valsartan and DOX on cardiac SMP-30 gene expression:}

SMP30 gene expression in the different groups was demonstrated in Figure 3. Valsartan did not change the SMP30 gene expression $(p>0.05)$ as compared with the control rats. DOX treatment significantly decreased SMP30 gene expression $(p<0.05)$ in comparison with both control groups. Administration of valsartan followed by DOX insignificantly $(p>0.05)$ change the DOX-induced reduction in SMP30 gene expression. Moreover, addition of valsartan with and after DOX significantly $(p<0.05)$ increased the SMP30 gene expression as compared with DOX induced animals either untreated or valsartan pretreated $(p<0.05)$ (figure 3). SMP30 gene expression showed a significant positive correlation with total anti-oxidants $(r=0.6983, p<0.05, n=60)$ (Figure $6 \mathrm{D})$ and a significant negative correlation with TBARS $(r=-0.6541, p<0.05, n=60)$ (Figure $6 \mathrm{E})$.

\section{Effects of valsartan and DOX on cardiac Bax gene expression:}

Valsartan treatment in the control rats caused no change $(p>0.05)$ in Bax gene expression as shown in figure 4. Also figure 4 showed that DOX administration either alone or after valsartan treatment increased Bax gene expression significantly $(p<0.05)$ as compared with the control rats. While valsartan administration with or after DOX decreased Bax gene expression significantly $(p<0.05)$ as compared with the DOX alone, values remains significantly $(p<0.05)$ higher than the control rats (figure 4). A significant negative correlation was reported between LVDP and Bax gene expression ( $r=-0.9572, p<0.0001, n=60$ ) (Figure $6 \mathrm{~A}$ ).

\section{Effects of valsartan and DOX on cardiac Bcl-2 gene expression:}

Compared to control rats, valsartan therapy did not change $(p>0.05) \mathrm{Bcl}-2$ gene expression as shown in figure 5. The Bcl-2 gene expression decreased significantly $(p<0.05)$ in rats exposed to DOX or valsartan pretreated group when compared with control group. Addition of valsartan with and after DOX significantly $(p<0.05)$ 
increased the $\mathrm{Bcl}-2$ gene expression but still significantly lower than the control rats $(p<0.05)$ (figure 5). Moreover, a significant positive correlation was observed between LVDP and Bcl-2 gene expression $(r=0.9571, p<0.0001$, $n=60$ ) (Figure $6 \mathrm{~B}$ ). In addition, a significant negative correlation was noticed between Bcl-2 gene expression and Bax gene expression $(r=-0.9167, p<0.0001, n=60)$ (Figure 6 C).

\section{Histopathological examination of cardiac tissues}

Heart sections of normal control rats showed normal characteristic features of myocardium without cellular infiltration and normal vasculature. Myocardiocyte of normal rats had oval-elongate nucleus centrally and homogeneous cytoplasm (Fig. 7 A). Rats received valsartan showed also apparently normal myocardial features similar to that of normal control Rats (Fig. 7 B). In rats treated with DOX either alone or after vasartan, multi-focal vacuolar degeneration and necrosis were seen in the myocardial cells (Fig. $7 \mathrm{C}$ and D). Moreover, there were congestion of cardiac blood vessel and hyalinosis of its wall, in addition to granularity of the sarcoplasm of focal cardiac myocytes (Fig. $7 \mathrm{C}$ and D). In contrast, myocardial cell of rats treated with DOX either with or before valsartan revealed less damage (Fig. $7 \mathrm{E}$ and F).

\section{Discussion}

In the current work, we investigated the cardioprotective effect of valsartan before, during and after administration of DOX to rats. The results of this study showed that treatment with valsartan during and after but not before DOX reduces the cardiac marker enzymes (LDH and CK-MB), attenuates the oxidative stress (as confirmed by decreased TBARS and increased TAC), ameliorates apoptosis (as evidenced by decreased Bax and increased Bcl-2 gene expression) and improve senescence (as shown by increased SMP30 gene expression). It was interesting to note that giving valsartan after DOX is as good as giving it along with DOX, therefore, one would assume that concurrent treatment would have an extra effect of slowing down the cardiotoxicity even more. The non significant change in the studied parameters with pretreatment of DOX-induced rats by valsartan may be due to its short duration of pretreatment ( 2 weeks) as well as its short Tmax (2-4 hours) and half life (T1/2) (6 hours) (Bakris et al. 1999) along with the extended duration of administration of DOX (2 weeks) in our model.

Despite the development of several antitumor drugs, DOX continues to be an effective and widely used broad spectrum chemotherapeutic agent; however, its use is limited because of its serious dose-dependent cardiotoxicity which often leads to progressive heart failure with impaired contractility, arrhythmias, or sudden death (Smith et al. 2010). Retrospective analysis of three clinical trials with 630 breast carcinoma and small-cell 
lung carcinoma patients indicated that at a cumulative dose of $550 \mathrm{mg} / \mathrm{m} 2$, an estimated $26 \%$ of patients experienced DOX-related congestive heart failure (Swain et al. 2003). In the present study, rats were administered a cumulative dose of DOX (15mg/kg) in six equal intraperitoneal (i.p.) injections $(2.5 \mathrm{mg} / \mathrm{kg}, 3$ times a week for 2 weeks). The mechanisms of cardiac toxicity are not fully understood and are thought to include oxidative stress status leading to apoptosis of endothelial cells and cardiomyocytes (Mukhopadhyay et al. 2009). In addition, cellular senescence has been proposed as a novel mechanism of cardiotoxicity induced by DOX (Maejima et al. 2008).

Hemodynamics are important indicators of cardiac function. Hemodynamic changes are key indicators of both the systolic and the diastolic function of the heart. Among these indicators are $+\mathrm{d} p / \mathrm{dtmax}$, which reflects myocardial contractile function as well as $-\mathrm{d} p / \mathrm{d} t \max$ which reflect myocardial relaxation (Lai et al. 2013). Our hemodynamic examination revealed that DOX significantly decreased LVDP and $+\mathrm{d} p / \mathrm{d} t \mathrm{max}$ and increased -d $p / \mathrm{d} t$ max compared with the control group (Table 1) indicating the development of DOX-induced cardiac contractile dysfunction. Our results were in agreement with those of previous studies (Hole et al. 2014; Li et al. 2014). Moreover, valsartan treatment with and after but not before DOX significantly $(p<0.05)$ increased the LVDP and $+\mathrm{d} P / \mathrm{d} t$ max and decreased $-\mathrm{d} P / \mathrm{d} t$ max as compared with DOX treated rats (Table 1) indicating that valsartan has positive inotropic effects and mitigates the changes associated with chronic heart failure induced by DOX. Therefore, these observations suggest that valsartan improved the heart function of rats with DOX-induced injury. In a study by Akolkar et al. (2015), they investigated the effect of administration of valsartan for 13 weeks on DOXinduced cardiotoxicity in mice. They demonstrated that valsartan ameliorated the toxic effect of DOX. Also, Bozcali et al. (2012) reported that zofenopril, enalapril and valsartan exerted a cardioprotective effects against ischaemia/reperfusion injury as well as DOX cardiotoxicity through preserving left ventricular systolic pressure. Translating these basic science findings to the clinical field, a number of clinical studies have evaluated the potential cardioprotective role of RAS antagonists in the clinical setting of chemotherapy mediated cardiotoxicity. A previous study have reported no change in blood pressure and heart rate between the valsartan and control groups in the patients treated with valsartan together with standard chemotherapy (CHOP) (Nakamae et al. 2005). Therefore, they concluded that the beneficial effects of valsartan on acute cardiotoxicity may be mediated not indirectly by its hemodynamic effects but by the direct inhibition of angiotensin II, supporting previous animal experiments demonstrating a key role of the local renin-angiotensin system in DOX-induced cardiac injury (Toko et al. 2002). 
ECG alterations were monitored in this study because it was demonstrated that the severity of changes in ECG are parallel to the known clinical DOX cardiotoxicity (Nousiainen et al. 1999). In the present study, ECG tracing of rats in the DOX group showed tachycardia, along with prolongation of ST, QT and QTc intervals (Table 2), which reflected arrhythmias, conduction abnormalities and attenuation of left ventricular function. Similar changes have been reported by other investigators (Ashour et al. 2011). The increased heart rate of DOX-treated rats can lead to increase in oxygen consumption and can accelerate myocardial necrosis. This suggestion is in line with the deteriorated histopathological features observed in DOX-treated rats (Fig. 7C).

A number of studies reported that the significant prolongation of the QTe interval in ECG may be important as it is known sensitive markers for chronic cardiac injury observed in ischemic and hypertensive heart disease, as well as in anthracycline-associated cardiac injury (Nakamae et al. 2005). According to Rossi et al. (1994), the reliable ECG changes noted with cumulative dose of DOX were QT prolongation and T-wave flattening. Meanwhile, Villani et al. (1990) insisted on the significance of ST interval prolongation in evaluating the ECG signs of toxicity induced in rodents with chronic administration of DOX. Also, AbdElbaky et al. (2010) reported an increase in heart rate along with ST and QT segment prolongation in albino rats administered DOX for 2 weeks. All of these observations are in accordance with our results that revealed a significant increase in heart rate with prolongation of ST, QT and QTc intervals in rats treated with DOX (Table 2). Moreover, these ECG changes were ameliorated in the valsartan concurrent or post but not pre treatment groups, indicating the protective effect of valsartan.

Cytosolic enzymes such as CK-MB and LDH function as sensitive indices to evaluate the severity of myocardial injury. Increased activities of these enzymes in serum are indicative of cellular damage, loss of functional integrity, and/or permeability of cell membrane (Rohilla et al. 2012). The present study demonstrated that the activities of CK-MB and LDH in serum are significantly increased in DOX group compared with control group (Table 3). These results were in line with those of Iqbal et al. (2008) and Yu et al. (2013). In contrast, the reduction of DOX-induced increase in the activities of serum LDH and CK-MB by concurrent or post but not pre treatment of animals with valsartan indicates suppression of cardiac injury; thereby supporting that valsartan has cardioprotective properties.

There are several hypotheses to explain the mechanisms of DOX-induced cardiotoxicity, oxidative stress, which represents one of the major cellular responses to toxic insults, is believed to be a major factor 
(Mukhopadhyay et al. 2009). Different mechanisms of free radical formation by DOX have been postulated. One of these mechanisms implicates the formation of a semiquinone that yields superoxide radicals in the presence of oxygen (Ravi and Das 2004). Another possible pathway is a non-enzymatic one that involves reaction with iron. Iron-DOX complex can reduce oxygen to superoxide anion and hydrogen peroxide. Hydrogen peroxide subsequently leads to the formation of hydroxyl radicals, which is considered to be most damaging and greatly enhances lipid peroxidation (Malisza and Hasinoff 1995). Lipid peroxidation has been defined as the oxidative deterioration of polyunsaturated lipid. Since the major components of biological membranes are lipids, their peroxidation can result in cell damage and death (Winczura et al. 2012). Malondialdehyde (MDA) is an end-product of lipid breakdown caused by oxidative stress, and its content in tissues is considered to be a good indicator of radical-induced lipid peroxidation (Giera et al. 2012). The results of the present study showed a significant increase of cardiac TBARS content with decrease of anti-oxidants in DOX-treated rats (Figures 1 and 2), suggesting the primary role of oxidative stress in DOX cardiotoxicity. These data are in agreement with earlier studies (Yu et al. 2013). Moreover, the reactive oxygen species (ROS) leads to depletion of the endogenous antioxidant system and oxidative injury. Superoxide dismutase, glutathione peroxidase and catalase constitute the first line of cellular defense against ROS, because they can decompose superoxide anions and hydrogen peroxide before their interaction to form the more reactive hydroxyl radical (Yu et al. 2013). In accordance with these studies, the results of the current work demonstrated a significant decrease in the cardiac total anti-oxidants in DOX-treated animals (Figures 1 and 2). However, concurrent or post but not pre treatment of DOX-induced rats with valsartan significantly decreased the TBARS and increased the total anti-oxidants (Figures 1 and 2), indicating that valsartan protects myocardium against DOX-induced cardiotoxicity through its anti-oxidative activity. In support for our results, El Maraghy et al. (2014) reported that valsartan treatment increased significantly aortic antioxidant parameters in 2K1C hypertensive rats suggesting an antioxidant activity of valsartan. In addition, Aslam and colleagues (2006) have shown that valsartan therapy significantly reduced plasma oxidative markers in hypertensive patients with end-stage renal disease. Similarly, Hirooka et al. (2008) have recently shown that valsartan therapy improved large-artery endothelial dysfunction by modulation of oxidative stress.

The biochemical alterations were confirmed by the pathological changes noted in myocardial tissue. These pathological changes have a unique diagnostic significance for heart failure, as they reflect the pathological damage inflicted on myocardial cells. Our present study showed multi-focal vacuolar degeneration and necrosis in the 
myocardial cells of DOX-treated rats. Moreover, there were congestion of cardiac blood vessel and hyalinosis of its wall, in addition to granularity of the sarcoplasm of focal cardiac myocytes in those rats. Also, in DOX-treated rats, the arrangement of myocardial cells was disordered, and inflammatory cells infiltrated areas around the myocardial cells (Fig. 7 C). However, each of these pathological alterations was mitigated by valsartan treatment with or after (Fig. $7 \mathrm{E}$ and F) but not before (Fig. $7 \mathrm{D}$ ) DOX, indicating that valsartan concurrent or post but not pre treatment exerts protective effects on myocardial cells.

It has been reported that numerous signaling molecules, such as cytochrome $c, \mathrm{Bcl}-2, \mathrm{Bax}, \mathrm{p} 53$, and Fas, have been implicated in the apoptotic pathways of cardiomyocytes (Abd El-Gawad and El-Sawalhi 2004). Bcl-2 family members include Bax, Bcl-2, and Bcl-xl. Bcl-2 was the first cell survival factor discovered in mammals, as it functions as an anti-apoptotic gene ( $\mathrm{Li}$ et al. 2014). When the ratio of Bcl-2/Bax is increased, the dimer facilitates cell survival; however, when the ratio is decreased, the dimer facilitates apoptosis ( $\mathrm{Li}$ et al. 2014). Therefore, the ratio of Bcl-2 to Bax may be a key regulator of apoptosis. In addition, the low ratio of Bcl-2 to Bax can activate caspase-3, which causes cleavage of cytoskeletal and nuclear proteins, and nucleosomal fragmentation (Shi et al. 2013). In the current work, our results revealed that DOX could induce cardiomyocyte apoptosis, as evaluated by decreased Bcl-2 and increased Bax gene expression (Figures 4 and 5), suggesting that apoptosis is one of the major contributors of DOX-imposed cardiac toxicity. These results were in agreement with previous studies (Yu et al. 2013). Accumulated data suggest that cardiomyocyte apoptosis and death in response to DOX are mainly mediated by increased oxidative stress (Smith et al. 2010). A significant negative correlation between Bax gene expression and LVDP (Figure 6 A) and a positive correlation between Bcl-2 gene expression and LVDP was reported (Figure 6 B) which may suggest that apoptosis contributes to the diminished cardiac contractile function in DOX-treated rats. It has already been reported that blocking the apoptosis process can prevent the loss of contractile cells and minimize myocardial injury after DOX injection (Chen et al. 2012). In support for these reports, we found that concurrent or post but not pretreatment with valsartan significantly attenuates DOX-induced cardiomyocyte apoptosis, as evidenced by the significant increase in Bcl-2 and decrease in Bax gene expression (Figures 4 and 5), implying that inhibition of apoptosis contributes to the mechanism by which valsartan restrains the extent of DOXinduced toxicity to myocardium.

SMP30, a 34-kDa protein, was originally identified as a novel aging marker protein in rat liver, whose expression decreases androgen-independently with age. SMP30 transcripts are detected in almost all organs, and the 
SMP30 gene is highly conserved among numerous animal species including humans. Earlier report suggests that SMP30 too plays a diverse role in proliferation, survival and differentiation of the cells (Yamaguchi 2000). It has been demonstrated that SMP30 plays multifunctional roles as $\mathrm{Ca} 2+$ regulator, anti-oxidants and gluconolactonase which is a key enzyme in the ascorbic acid (vitamin C) biosynthesis (Miyata et al. 2013). The lack of SMP30 causes various dysfunctions of organs during aging process (Miyata et al. 2013). SMP30 knockout (SMP30 KO) mice were generated (Ishigami et al. 2002) and showed a shorter life span than that of wild-type mice on a vitamin C-deficient diet (Ishigami et al. 2004). Using SMP30 KO mice, recent reports have demonstrated that SMP30 functions to protect cells from apoptosis in the liver (Ishigami et al. 2002) and that SMP30 has protective effects against ageassociated oxidative stress in the brain (Son et al. 2006) and lungs (Sato et al. 2006). In support for the anti-oxidant effect of SMP30 reported by the previous studies (Miyata et al. 2013; Sato et al. 2006; Son et al. 2006), our results demonstrated a significant positive correlation between SMP30 and anti-oxidants (Figure 6 D) and negative correlation between SMP30 and TBARS (Figure 6 E) which may suggest the anti-oxidant effect of SMP30 in the DOX-induced cardiac oxidative stress. Also, it was reported that SMP30 deficiency independent of ascorbic acid causes coronary artery spasms that are triggered by chronic thiol oxidation (Yamada et al. 2013) and impairs myocardium-induced dilation of coronary arterioles (Mizukami et al. 2013). Therefore, SMP30 is assumed to behave as an anti-aging factor. Recently, Misaka et al. (2011) have demonstrated that deficiency of SMP30 exacerbates angiotensin II-induced cardiac hypertrophy, dysfunction and remodeling in mice. In addition, SMP30 is reported to have a cardio-protective role against DOX-associated cardiac dysfunction by inhibiting oxidative stress and cardiac cell apoptosis (Miyata et al. 2013). In accordance with these studies, the results of the current work demonstrated a significant decrease in SMP30 gene expression in DOX-treated rats (Figure 3), suggesting that reduced SMP30 may play a role in DOX-induced cardiotoxicity. Concurrent or post but not pre treatment of DOXinduced rats with valsartan caused a significant increase in SMP30 gene expression (Figure 3), implying that the cardio-protective effect of valsartan may be partly attributed to increase in SMP30 gene expression.

There were some limitations to our study. First, in our study we administered valsartan for 14 days which appeared to be short duration compared with Akolkar et al. (2015) who administered valsartan and other angiotensin II receptor blockers for 13 weeks in mice. Second, the use of other types of angiotensin receptor blockers and angiotensin converting enzyme inhibitors is required. Finally, one of the shortcomings in our study is inability to 
assess telomerase activity, cell cycle inhibitor expression, cardiac troponin I phosphorylation and senescenceassociated $\beta$-galactosidase staining.

In conclusion, DOX induced cardiotoxicity could be attributed to oxidative stress, apoptosis and senescence. In addition, concurrent or post but not pre treatment with valsartan attenuated DOX-induced cardiotoxicity through suppression of oxidative stress, apoptosis and senescence. 


\section{References}

AbdElbaky, N.A., Ali, A.A., and Ahmed, R.A. 2010. Cardioprotective effect of simvastatin on doxorubicin-induced oxidative cardiotoxicity in rats. J. Basic Appl. Sci. 6(1):29-38.

Abd El-Gawad, H.M., and El-Sawalhi, M.M. 2004. Nitric oxide and oxidative stress in brain and heart of normal rats treated with doxorubicin: role of aminoguanidine. J. Biochem. Mol. Toxicol. 18:69-77. PMID: 15122648

Akolkar, G., Bhullar, N., Bews, H., Shaikh, B., Premecz, S., Bordun, K.A., Cheung, D.Y., Goyal, V., Sharma, A.K., Garber, P., Singal, P.K., and Jassal, D.S. 2015. The role of renin angiotensin system antagonists in the prevention of doxorubicin and trastuzumab inducedcardiotoxicity. Cardiovasc. Ultrasound, Apr 3;13:18. doi: 10.1186/s12947-015-0011-x.

Arruda, L.F., Arruda, S.F., Campos, N.A., de Valencia, F.F., and Siqueira, E.M. 2013. Dietary Iron Concentration May Influence Aging Process by Altering Oxidative Stress in Tissues of Adult Rats. PLoS ONE, 8(4): e61058.PMID: 23593390.

Ashour, O.M., Elberry, A.A., Alahdal, A.M., Al Mohamadi, A.M., Nagy, A.A., Abdel-Naim, A.B., Abdel-Sattar, E.A., and Mohamadin, A.M. 2011. Protective effect of bilberry (Vacciniummyrtillus) against doxorubicininduced oxidative cardiotoxicity in rats. Med. Sci. Monit. 17(4):BR110-115. PMCID: PMC3539517.

Aslam, S., Santha, T., Leone, A., and Wilcox, C. 2006. Effects of amlodipine and valsartan on oxidative stress and plasma methylarginines in end-stage renal disease patients on hemodialysis. Kidney Int. 70(12):210915.PMID: 17063175

Bakris, G.L., Giles, T.D., and Weber, M.A. 1999. Clinical efficacy and safety profiles of AT1 receptor antagonists. Cardiovasc. Rev. Reports, 20(2):77-120.

Bozcali, E., Dedeoglu, D.B., Karpuz, V., Suzer, O., and Karpuz, H. 2012. Cardioprotective effects of zofenopril, enalapril and valsartan against ischaemia/reperfusion injury as well as doxorubicin cardiotoxicity. Acta Cardiol. 67(1):87-96.

Burnier, M., and Brunner, H.R. 2000. Angiotensin II receptor antagonists, Lancet, 355:637-645. PMCID: PMC1200815.

Chen, Y.L., Loh, S.H., Chen, J.J. and Tsai, C.S. 2012. Urotensin II prevents cardiomyocyte apoptosis induced by doxorubicin via Akt and ERK. Eur. J. Pharmacol. 680:88-94. PMCID: PMC4182104. 
Dessì, M., Piras, A., Madeddu, C., Cadeddu, C., Deidda, M., Massa, E., et al. 2011. Long-term protective effects of the angiotensin receptor blocker telmisartan on epirubicin-induced inflammation, oxidative stress and myocardial dysfunction. Exp.Ther. Med. 2:1003-9.

Eleawa, S.M., Sakr, H.F., Hussein, A.M., Assiri, A.S., Bayoumy, N.M., and Alkhateeb, M. 2013. Effect of testosterone replacement therapy on cardiac performance and oxidative stress in orchidectomized rats. Acta Physiol (Oxf), 209(2):136-47. doi: 10.1111/apha.12158. PMID: 24028646.

El Maraghy, N.N., Mahmoud, M.F., Sourour, D.A., and Abozaid, M.I. 2014. Beneficial Effects of Valsartan on Renovascular Hypertension in Rats via Nitric Oxide Preserving and Antioxidant Effects. International Journal of Advanced Research, 2(6):714-722.

Ferreira, A.L., Matsubara, L.S., and Matsubara, B.B. 2008. Anthracycline-induced cardiotoxicity. Cardiovasc. Hematol. Agents Med. Chem. 6:278-281.

Giera, M., Lingeman, H., and Niessen, W.M. 2012. Recent advancements in the LC- and GC- based analysis of malondialdehyde (MDA): a brief overview. Chromatographia, 75:433-440. PMID: 22593603.

Hirooka, Y., Kimura, Y., Sagara, Y., Ito, K., and Sunagawa, K. 2008. Effects of valsartan or amlodipine on endothelial function and oxidative stress after one year follow-up in patients with essential hypertension. Clin. Exp. Hypertens. 30(3): 267-76. PMID: 18425706.

Hole, L.D., Larsen, T.H., Fossan, K.O., Limé, F., and Schjøtt, J. 2014. Diazoxide protects against doxorubicininduced cardiotoxicity in the rat. BMC Pharmacol. Toxicol. 15:28. PMID: 24887454.

Huang, Q., Dunn, R.T., Jayadev, S., DiSorbo, O., and Pack, F.D. 2001. Assessment of cisplatin-induced nephrotoxicity by microarray technology. Toxicol. Sci. 63:196-207.

Iqbal, M., Dubey, K., Anwer, T., Ashish, A., and Pillai, K.K. 2008. Protective effects of telmisartan against acute doxorubicin-induced cardiotoxicity in rats. Pharmacol. Rep. 60:382-390. PMID: 18622063.

Ishigami, A., Fujita, T., Handa, S., Shirasawa, T., Koseki, H., et al. 2002. Senescence marker protein-30 knockout mouse liver is highly susceptible to tumor necrosis factor-alpha- and Fas-mediated apoptosis. Am. J. Pathol. 161:1273-128. PMID: 12368201.

Ishigami, A., Kondo, Y., Nanba, R., Ohsawa, T., Handa, S., et al. 2004. SMP30 deficiency in mice causes an accumulation of neutral lipids and phospholipids in the liver and shortens the life span. Biochem. Biophys. Res. Commun. 315:575-580. PMID: 14975739. 
Kalam, K., and Marwick, T.H. 2013. Role of cardioprotective therapy for prevention of cardiotoxicity with chemotherapy: a systematic review and meta-analysis. Eur. J. Cancer, 49:2900-9.

Katalinic, V., Modun, D., Music, I., and Boban, M. 2005. Gender differences in antioxidant capacity of rat tissues determined by 2, 2 V-azinobis (3-ethylbenzothiazoline 6-sulfonate; ABTS) and ferric reducing antioxidant power (FRAP) assays. Comp. Biochem. Physiol. C 140: 47-52· DOI: 10.1016/j.cca.2005.01.005.

Khan, M.A., and Imig, J.D. 2011. Telmisaratan provides better renal protection than valsartan in a rat model of metabolic Syndrome. Am. J. Hypertens. 24(7):816-821. PMID: 21415842.

Lai, Y., Wu, H.J., Zheng, S.D., and Wu, D.L. 2013. The hemodynamic effects on chronic heart failure rats with Shen Fu Tang. Jilin. J. Tradit. Chin. Med. 33:276-77.

Li, G.Y., Xie, P., Li, H.Y., Hao, L., Xiong, Q., and Qiu, T. 2011. Involvement of p53, Bax, and Bcl-2 pathway in microcystins-induced apoptosis in rat testis. Environ. Toxicol. 26(2):111-7. doi: 10.1002/tox.20532. PMID: 19760617.

Li, Y., Song, P., Zhu, Q., Yin, Q., Ji, J., Li, W., and Bian, H. 2014. Liguzinediol improved the heart function and inhibited myocardial cell apoptosis in rats with heart failure. Acta Pharmacologica Sinica, 35:1257-1264. PMID: 25220638.

Maejima, Y., Adachi, S., Ito, H., Hirao, K., and Isobe, M. 2008. Induction of premature senescence in cardiomyocytes by doxorubicin as a novel mechanism of myocardial damage. Aging Cell, 7:125-136. PMID: 18031568 .

Malisza, K.L., and Hasinoff, B.B. 1995. Production of hydroxyl radical by iron (III)-anthraquinone complexes through self-reduction and through reductive activation by the xanthine oxidase/hypoxanthine system. Arch. Biochem. Biophys. 321: 51-60. PMID: 7639535.

Misaka, T., Suzuki, S., Miyata, M., Kobayashi, A., Saitoh, S., et al. 2011. Senescence marker protein 30 inhibits angiotensin II-induced cardiac remodeling. Circulation, 124:A8880. PMID: 23933320.

Miyata, M., Suzuki, S., Misaka, T., Shishido, T., Saitoh, S., Ishigami, A., Kubota, I., and Takeishi, Y. 2013. Senescence marker protein 30 has a cardio-protective role in doxorubicin-induced cardiac dysfunction. PLoS One, 8(12):e79093. PMID: 24391705.

Mizukami, H., Saitoh, S., Machii, H., Yamada, S., Hoshino, Y., Misaka, T., Ishigami, A., and Takeishi, Y. 2013. Senescence marker protein-30 (SMP30) deficiency impairs myocardium-induced dilation of 
coronary arterioles associated with reactive oxygen species. Int. J. Mol. Sci. 14:9408-9423. PMCID: PMC3676790.

Mukhopadhyay, P., Rajesh, M., Bátkai, S., Kashiwaya, Y., Haskó, G., Liaudet, L., et al. 2009. Role of superoxide, nitric oxide, and peroxynitrite in doxorubicin-induced cell death in vivo and in vitro. Am. J. Physiol. 296:H1466-83. PMID: 19286953.

Nakamae, H., Tsumura, K., Terada, Y., Nakane, T., Nakamae, M., Ohta, K., Yamane, T., and Hino, M. 2005. Notable effects of Angiotensin II Receptor Blocker, Valsartan, on Acute Cardiotoxic Changes after Standard Chemotherapy with Cyclophosphamide, Doxorubicin, Vincristine, and Prednisolone. Cancer, 104 (11): 2492-2498. PMID: 16247790.

Nousiainen, T., Vanninen, E., Ranrala, A., Jantunen, E., and Hartikainen, J.1999. QT dispersion and late potentials during doxorubicin therapy for non-Hodgkin's lymphoma. J. Intern. Med. 245:359-364. PMID: 10356598.

Octavia, Y., Tocchetti, C.G., Gabrielson, K.L., Janssens, S., Crijns, H.J., and Moens, A.L. 2012. Doxorubicininduced cardiomyopathy: from molecular mechanisms to therapeutic strategies. J. Mol. Cell. Cardiol. 52:1213-1225. PMID: 22465037.

Rattan, S.I.S. 2012. Cell senescence in vitro. Encyclopedia of life sciences (eLS). Wiley.

Ravi, D., and Das, K.C. 2004. Redox-cycling of anthracyclines by thioredoxin system: increased superoxide generation and DNA damage. Cancer Chemother. Pharmacol. 54: 449-58. PMID: 15290096.

Rohilla, A., Khan, M.U., and Khanam, R. 2012. Cardioprotective potential of simvastatin in the hyperhomocysteinemic rat heart. J. Adv. Pharm. Technol. Res. 3:193-198. PMID: 23057007.

Rossi, F., Filipelli, W., Russo, S., Filippelli, A., and Berrino, L. 1994. Cardiotoxicity of doxorubicin: effects of drugs inhibiting the release of vasoactive substances. Pharmacol. Toxicol. 75:99-107. PMID: 7971744.

Sato, T., Seyama, K., Sato, Y., Mori, H., and Souma, S. 2006. Senescence marker protein-30 protects mice lungs from oxidative stress, aging, and smoking. Am. J. Respir. Crit. Care. Med. 174:530-537. PMID: 16728709.

Shi, K., Wang, D., Cao, X., and Ge, Y. 2013. Endoplasmic reticulum stress signaling is involved in mitomycin C (MMC)-induced apoptosis in human fibroblasts via PERK pathway. PLoS One, 8:e59330.PMID: 23533616. 
Siveski-Iliskovic, N., Kaul, N., and Singal, P.K. 1994. Probucol promotes endogenous antioxidants and provides protection against adriamycin-induced cardiomyopathy in rats. Circulation, 89:2829-2835. PMID: 8205698

Smith, L.A., Cornelius, V.R., Plummer, C.J., Levitt, G., Verrill, M., et al. 2010. Cardiotoxicity of anthracycline agents for the treatment of cancer: Systematic review and meta-analysis of randomised controlled trials. BMC Cancer, 10: 337. PMID: 20587042.

Son, T.G., Zou, Y., Jung, K.J., Yu, B.P., Ishigami, A., et al. 2006. SMP30 deficiency causes increased oxidative stress in brain. Mech. Ageing Dev. 127:451-457.PMID: 16500693.

Spallarossa, P., Altieri, P., Aloi, C., Garibaldi, S., Barisione, C., Ghigliotti, G., Fugazza, G., Barsotti, A., and Brunelli,C. 2009. Doxorubicin induces senescence or apoptosis in rat neonatal cardiomyocytes by regulating the expression levels of the telomere binding factors 1 and 2. Am. J. Physiol. 297: H2169H2181. PMID: 19801496

Swain, S.M., Whaley, F.S., and Ewer, M.S. 2003. Congestive heart failure in patients treated with doxorubicin: a retrospective analysis of three trials. Cancer, 97: 2869-79. PMID: 12767102.

Toko, H., Oka, T., Zou, Y., Sakamoto, M., Mizukami, M., Sano, M., Yamamoto, R. et al. 2002. Angiotensin II type Ia receptor mediates doxorubicin-induced cardiomyopathy. Hypertens. Res. 25:597-603. PMID: 12358147.

Vaynblat, M., Shah, H.R., Bhaskaran, D., et al. 2002. Simultaneous angiotensin converting enzyme inhibition moderates ventricular dysfunction caused by doxorubicin. Eur. J. Heart Fail. 4:583-586. PMID: 12413500.

Villani, F., Galimberti, M., Monti, E., Cova, D., Lanza, E., and Rozza- Dionigi, A. 1990. Effects of ICRF-187 pretreatment against doxorubicin-induced delayed cardiotoxicity in the rat. Toxicol. Appl. Pharmacol. 102: 292-299. PMID: 2105541.

Volkova, M., and Russell, R. 2011. Anthracycline cardiotoxicity: prevalence, pathogenesis and treatment. Curr. Cardiol. Rev. 7: 214 - 220. PMID: 22758622.

Wang, Q., Du, F., Qian, Z.M., Ge, X.H., Zhu, L., et al. 2008. Lipopolysaccharide induces a significant increase in expression of iron regulatory hormone hepcidin in the cortex and substantia nigra in rat brain. Endocrinology, 149:3920-3925. PMID: 18450970.

Winczura, A., Zdzalik, D., and Tudek, B. 2012. Damage of DNA and proteins by major lipid peroxidation products in genome stability. Free Radic. Res. 46:442-459. PMID: 22257221. 
Yamada, S., Saitoh, S., Machii, H., Mizukami, H., Hoshino, Y., Misaka, T., Ishigami, A., and Takeishi, Y. 2013. Coronary artery spasm related to thiol oxidation and senescence marker protein-30 in aging. Antioxid. Redox. Signal. 19:1063-1073. PMID: 23320823.

Yamaguchi, M. 2000. The role of regucalcin in nuclear regulation of regenerating liver. Biochem. Biophys. Res. Commun. 276:1-6. PMID: 11006072.

Yoshioka, T., Kawada. K., Shimada, T., and Mori, M. 1979. Lipid peroxidation in maternal and cord blood and protective mechanism against activated-oxygen toxicity in the blood. Am. J. Obst. Gynecol. 135:372-376. PMID: 484629 .

Yu, X., Cui, L., Zhang, Z., Zhao, Q., and Li, S. 2013. $\alpha$-Linolenic acid attenuates doxorubicin-induced cardiotoxicity in rats through suppression of oxidative stress and apoptosis. Acta. Biochim. Biophys. Sin. 45(10):817-826. PMID: 23896563.

Zablocki, D., and Sadoshima, J. 2013. Angiotensin II and oxidative stress in the failing heart. Antioxid Redox Signal. 19(10):1095-109. doi: 10.1089/ars.2012.4588. Epub 2012 May 3. PMCID: PMC3771547 


\section{Tables}

Table 1: Contractile variables (LVDP, $\mathrm{dP} / \mathrm{dtmax}$ and - $\mathrm{dP} / \mathrm{dtmax}$ ) obtained from Langendorff isolated hearts from all groups of rats.

\begin{tabular}{|l|l|l|l|l|l|l|}
\hline Parameter & Control & $\begin{array}{l}\text { Control } \\
\text { valsartan }\end{array}$ & DOX. & $\begin{array}{l}\text { Valsartan } \\
\text { before DOX. }\end{array}$ & $\begin{array}{l}\text { Valsartan } \\
\text { DOX. }\end{array}$ & $\begin{array}{l}\text { with } \\
\text { Valsartan } \\
\text { DOX. }\end{array}$ \\
\hline $\begin{array}{l}\text { LVDP } \\
(\mathrm{mmHg} / \mathrm{g} H W)\end{array}$ & $102.8 \pm 4.65$ & $105.7 \pm 6.8$ & $50.4 \pm 6.7^{\mathrm{ab}}$ & $56.7 \pm 6.5^{\mathrm{ab}}$ & $75.8 \pm 9.5^{\mathrm{abcd}}$ & $86.7 \pm 4.9^{\mathrm{abc}}$ \\
\hline $\begin{array}{l}\mathrm{dp} / \mathrm{dt} \max \\
(\mathrm{mmHg} / \mathrm{s})\end{array}$ & $2729.4 \pm 93.8$ & $2808.5 \pm 100.7$ & $1325.7 \pm 49.8^{\mathrm{ab}}$ & $1427.4 \pm 66.3^{\mathrm{ab}}$ & $2209 \pm 82.8^{\mathrm{abcd}}$ & $2407 \pm 86.2^{\mathrm{abc}}$ \\
\hline $\begin{array}{l}\mathrm{dp} / \mathrm{dt} \max \\
(\mathrm{mmHg} / \mathrm{s})\end{array}$ & $-1798.4 \pm 89.4$ & $-1805.4 \pm 80.6$ & $-986.3 \pm 55.9^{\mathrm{ab}}$ & $-1006.7 \pm 59.7^{\mathrm{ab}}$ & $-1109.1 \pm 87.2^{\mathrm{abcd}}$ & $-1396.4 \pm 84.7^{\mathrm{abc}}$ \\
\hline
\end{tabular}

Data are expressed as Mean \pm S.D. DOX: Doxorubicin, LVDP:left ventricular developed pressure
a: $P<0.05$ versus control.
b: $P<0.05$ versus control+ valsartan group.
c: $P<0.05$ versus DOX group.
d: $P<0.05$ versus valsartan before DOX group 
Table 2: Heart rate and different ECG parameters in all groups of rats

\begin{tabular}{|l|l|l|l|l|l|l|}
\hline Parameter & Control & $\begin{array}{l}\text { Control } \\
\text { valsartan }\end{array}$ & DOX. & $\begin{array}{l}\text { Valsartan } \\
\text { before DOX. }\end{array}$ & $\begin{array}{l}\text { Valsartan with } \\
\text { DOX. }\end{array}$ & $\begin{array}{l}\text { Valsartan after } \\
\text { DOX. }\end{array}$ \\
\hline ST (ms) & $9.2 \pm 0.3$ & $9.3 \pm 0.4$ & $13.4 \pm 0.3^{\text {ab }}$ & $13.8 \pm 0.2^{\text {ab }}$ & $10.2^{\text {cd }} \pm 0.2^{\text {cd }}$ & $9.8 \pm 0.4^{\text {cd }}$ \\
\hline QT (ms) & $75.5 \pm 2.3$ & $77.5 \pm 3.12$ & $96.3 \pm 2.8^{\text {ab }}$ & $97.4 \pm 2.1^{\text {ab }}$ & $79.4 \pm 2.4^{\text {cd }}$ & $78.4 \pm 3.6^{\text {cd }}$ \\
\hline QTc (ms) & $173.4+11.2$ & $179.6 \pm 12.1$ & $247.3 \pm 14.3^{\text {ab }}$ & $245.4 \pm 13.4^{\text {ab }}$ & $193.8 \pm 10.3^{\text {cd }}$ & $189.4 \pm 2.8^{\text {cd }}$ \\
\hline QRS (ms) & $24.3 \pm 0.8$ & $23.1 \pm 0.9$ & $21.7 \pm 1.2$ & $21.4 \pm 1.5$ & $22.5 \pm 1.1$ & $22.9 \pm 1.4$ \\
\hline $\begin{array}{l}\text { Heart rate } \\
\text { (beats } \backslash \text { min) }\end{array}$ & $315.7 \pm 6.9$ & $319.4 \pm 7.2$ & $396.5 \pm 9.2^{\text {ab }}$ & $380.4 \pm 8.1^{\text {ab }}$ & $356.9 \pm 8.4^{\text {abcd }}$ & $348.4 \pm 6.9^{\text {abcd }}$ \\
\hline
\end{tabular}

Data are expressed as Mean \pm S.D. DOX.: Doxorubicin
a: $P<0.05$ versus control.
b: $P<0.05$ versus control+ valsartan group.
c: $P<0.05$ versus DOX group.
d: $P<0.05$ versus valsartan before DOX group 
Table 3: serum level of LDH and CK-MB in all groups of rats

\begin{tabular}{|c|c|c|c|c|c|c|}
\hline Parameter & Control & $\begin{array}{ll}\text { Control } & + \\
\text { valsartan }\end{array}$ & DOX. & $\begin{array}{l}\text { Valsartan } \\
\text { before DOX. }\end{array}$ & $\begin{array}{l}\text { Valsartan with } \\
\text { DOX. }\end{array}$ & $\begin{array}{l}\text { Valsartan after } \\
\text { DOX. }\end{array}$ \\
\hline $\begin{array}{l}\text { LDH } \\
(\mathrm{U} / \mathrm{L})\end{array}$ & $74.5 \pm 4.2$ & $71.3 \pm 5.1$ & $158.4 \pm 10.1^{\mathrm{ab}}$ & $147.4 \pm 9.3^{\mathrm{ab}}$ & $103.6 \pm 7.5^{\mathrm{abcd}}$ & $96.6 \pm 6.7^{\mathrm{abcd}}$ \\
\hline $\begin{array}{l}\text { CK-MB } \\
\text { (U/L) }\end{array}$ & $84.3 \pm 6.1$ & $86.3 \pm 5.4$ & $186.4 \pm 13.1^{\mathrm{ab}}$ & $178.9 \pm 12.8^{\mathrm{ab}}$ & $110.3 \pm 8.1^{\mathrm{abcd}}$ & $105.3 \pm 6.8^{\mathrm{abcd}}$ \\
\hline
\end{tabular}

Data are expressed as Mean \pm S.D. DOX: Doxorubicin, LDH: lactate dehydrogenase, CK-MB: creatine kinase-MB
a: $P<0.05$ versus control.
b: $P<0.05$ versus control+ valsartan group.
c: $P<0.05$ versus DOX group.
d: $P<0.05$ versus valsartan before DOX group 


\section{Figure legends}

Figure 1: TBARS in all groups of rats
a: $P<0.05$ versus control.
b: $P<0.05$ versus control+ valsartan group.
c: $P<0.05$ versus DOX group.
d: $P<0.05$ versus valsartan before DOX group

Figure 2: total anti-oxidant capacity (TAC) in all groups of rats
a: $P<0.05$ versus control.
b: $P<0.05$ versus control+ valsartan group.
c: $P<0.05$ versus DOX group.
$\mathrm{d}: P<0.05$ versus valsartan before DOX group

Figure 3: Senescence marker protein 30 (SMP30) gene expression in all groups of rats
a: $P<0.05$ versus control.
b: $P<0.05$ versus control+ valsartan group.
c: $P<0.05$ versus DOX group.
$\mathrm{d}: P<0.05$ versus valsartan before DOX group

Figure 4: Bax gene expression in all groups of rats
a: $P<0.05$ versus control.
b: $P<0.05$ versus control+ valsartan group.
c: $P<0.05$ versus DOX group.
d: $P<0.05$ versus valsartan before DOX group.
e: $P<0.05$ versus valsartan with DOX group.

Figure 5: Bcl-2 gene expression in all groups of rats
a: $P<0.05$ versus control.
b: $P<0.05$ versus control+ valsartan group.
c: $P<0.05$ versus DOX group.
d: $P<0.05$ versus valsartan before DOX group. 
Figure 6: Pearson correlation coefficient

Figure 6 A: Pearson correlation coefficient between Bax gene expression and left ventricular developed pressure (LVDP). $(r=-0.9572)(p<0.0001)(n=60)$.

Figure 6 B: Pearson correlation coefficient between Bcl-2 gene expression and left ventricular developed pressure (LVDP). $(r=0.9571)(p<0.0001)(n=60)$.

Figure 6 C: Pearson correlation coefficient between Bax and Bcl-2 gene expression. $(r=-0.9167)(p<0.0001)$ $(n=60)$.

Figure 6 D: Pearson correlation coefficient between SMP30 gene expression and total anti-oxidant capacity (TAC). $(r=0.6983)(p<0.05)(n=60)$.

Figure 6 E: Pearson correlation coefficient between SMP30 gene expression and TBARS. $(r=-0.6541)(p<0.05)$ $(n=60)$.

Figure 7: Histological appearance of heart tissue sections obtained from all groups (A): control, (B): control+valsartan, (C): DOX, (D): valsartan before DOX, (E): valsartan + DOX and (E): valsartan after DOX; $(\mathrm{H} \& \mathrm{E} \times 100)$. 


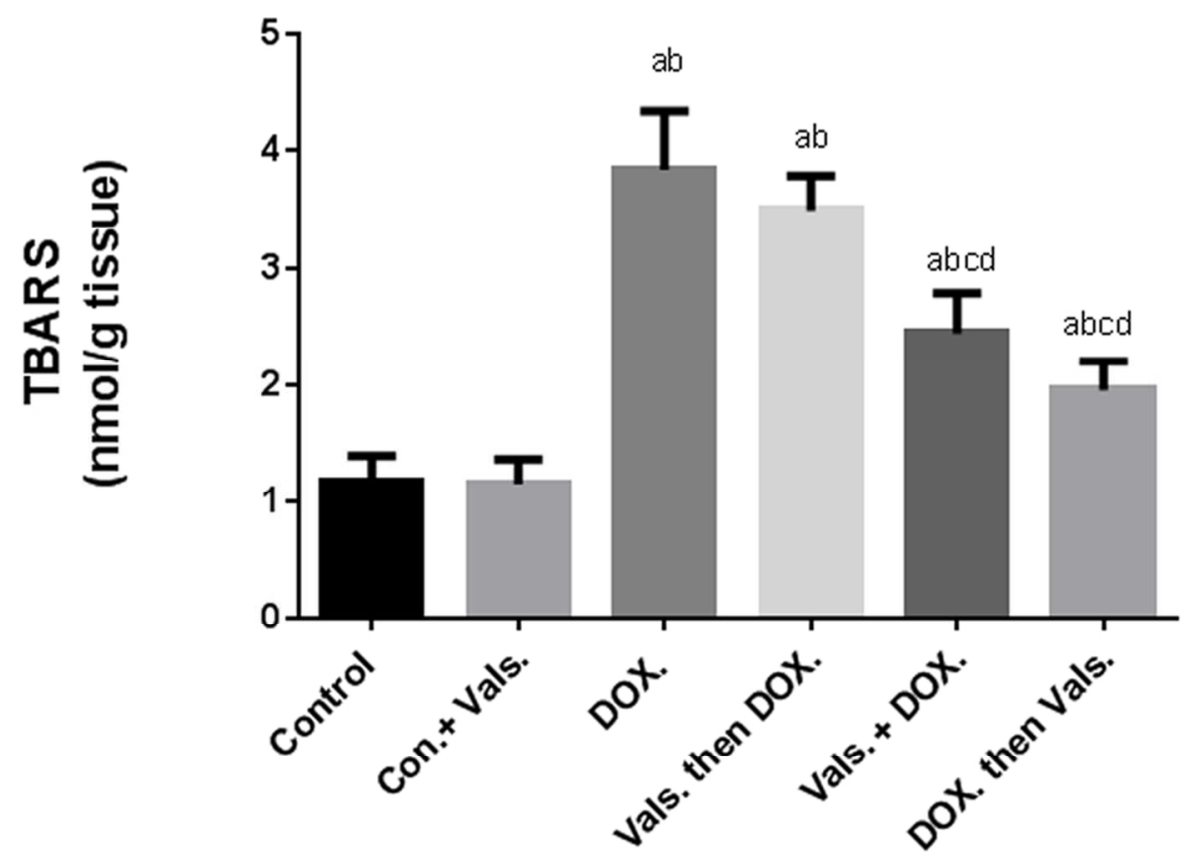

Figure 1.

$90 \times 63 \mathrm{~mm}(300 \times 300$ DPI $)$ 


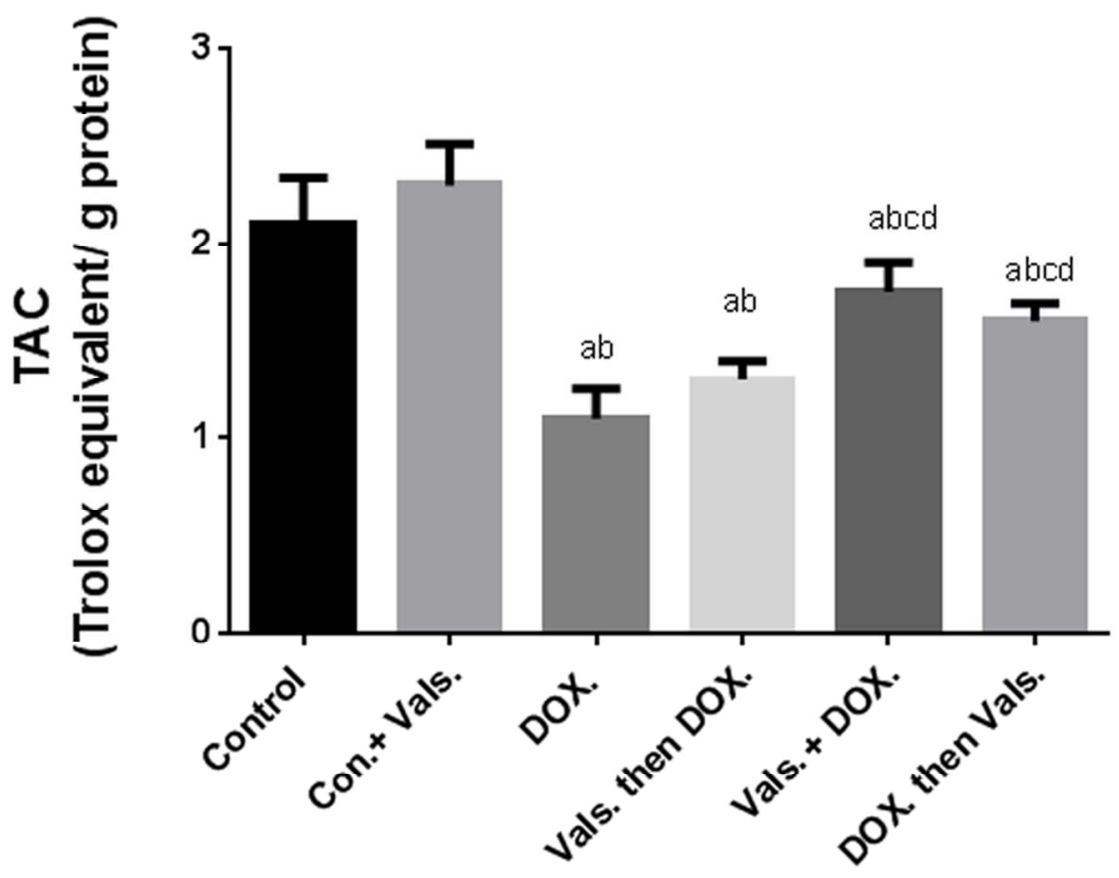

Figure 2 .

$90 \times 63 \mathrm{~mm}(300 \times 300 \mathrm{DPI})$ 


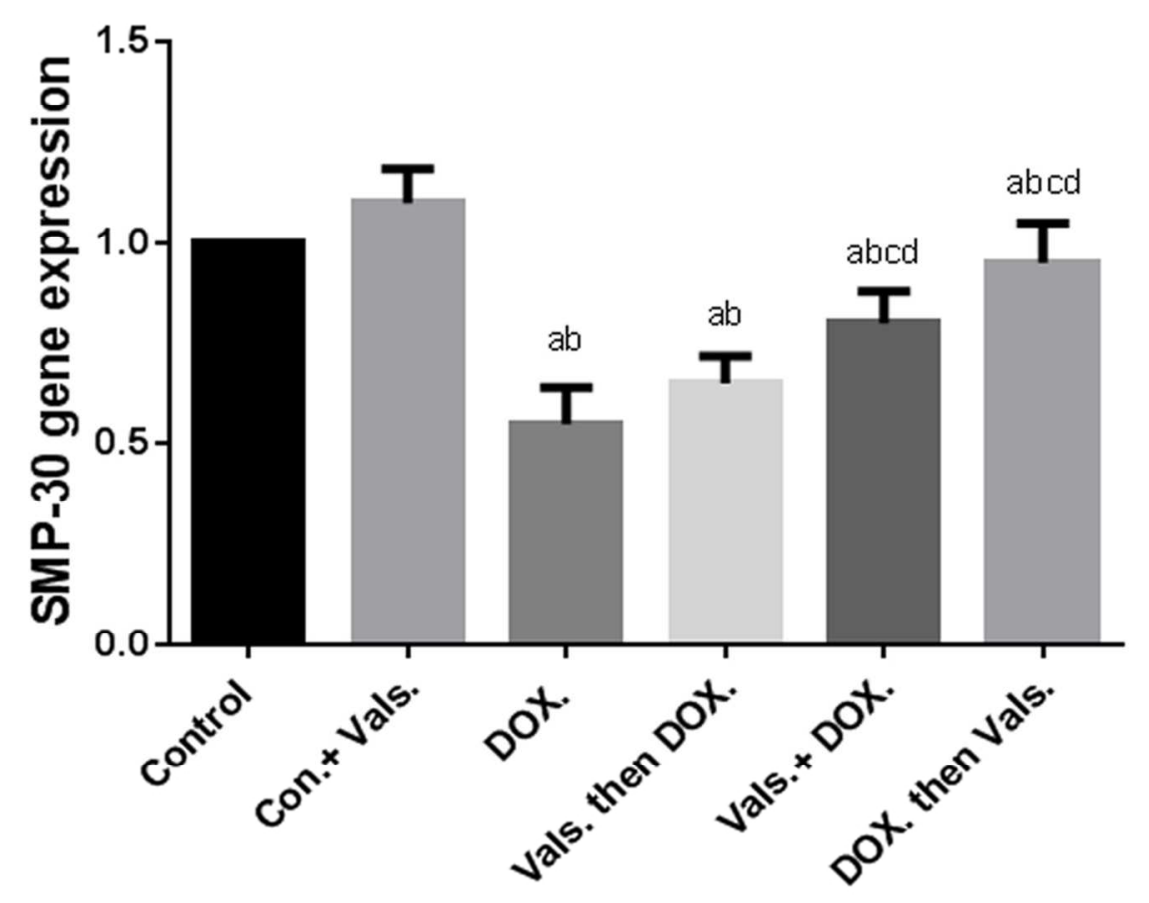

Figure 3.

$90 \times 63 \mathrm{~mm}(300 \times 300 \mathrm{DPI})$ 


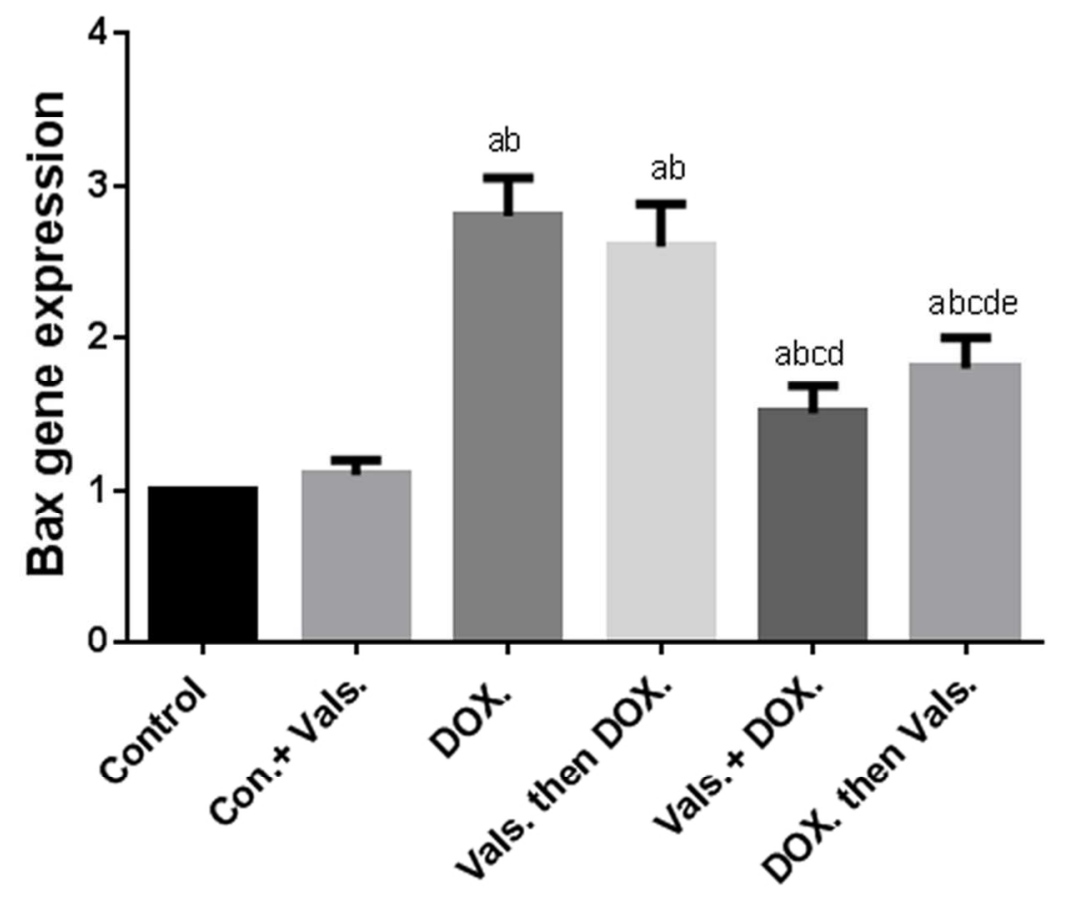

Figure 4

$90 \times 63 \mathrm{~mm}(300 \times 300 \mathrm{DPI})$ 


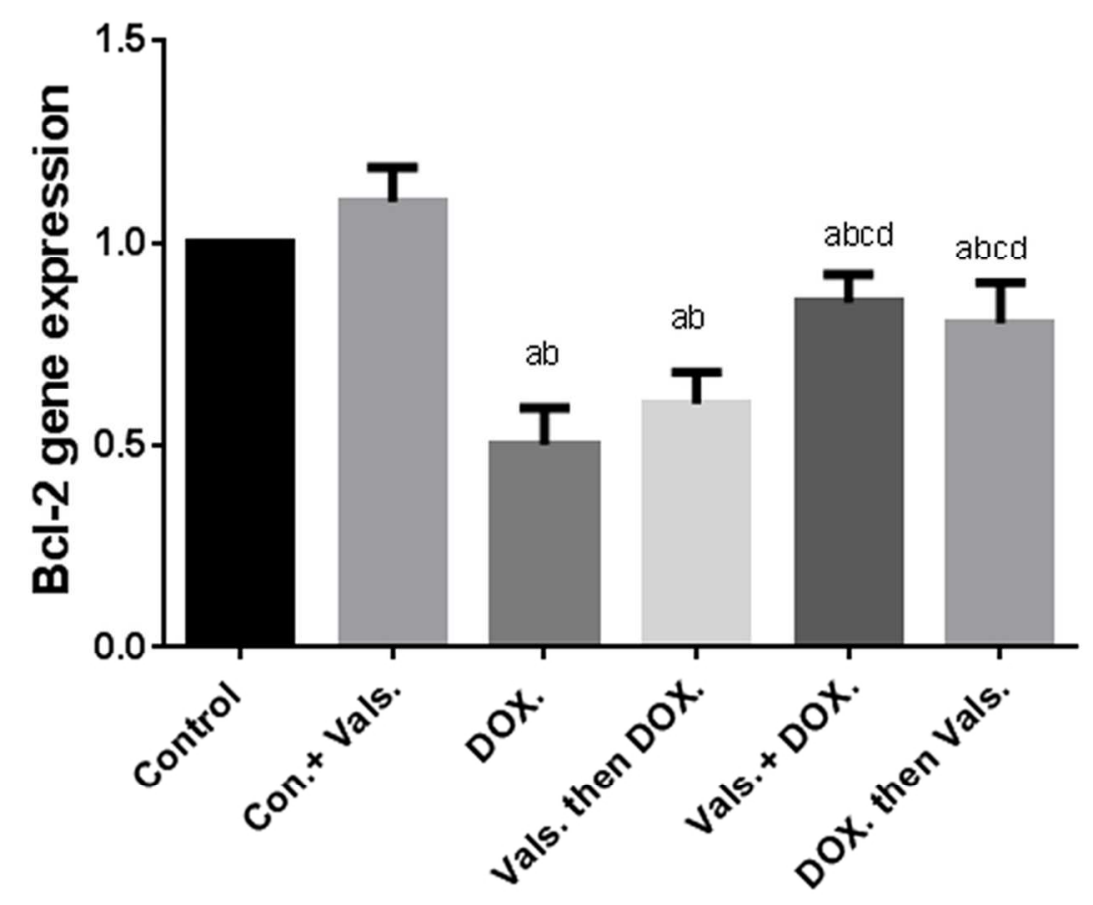

Figure 5 .

$90 \times 63 \mathrm{~mm}(300 \times 300$ DPI $)$ 


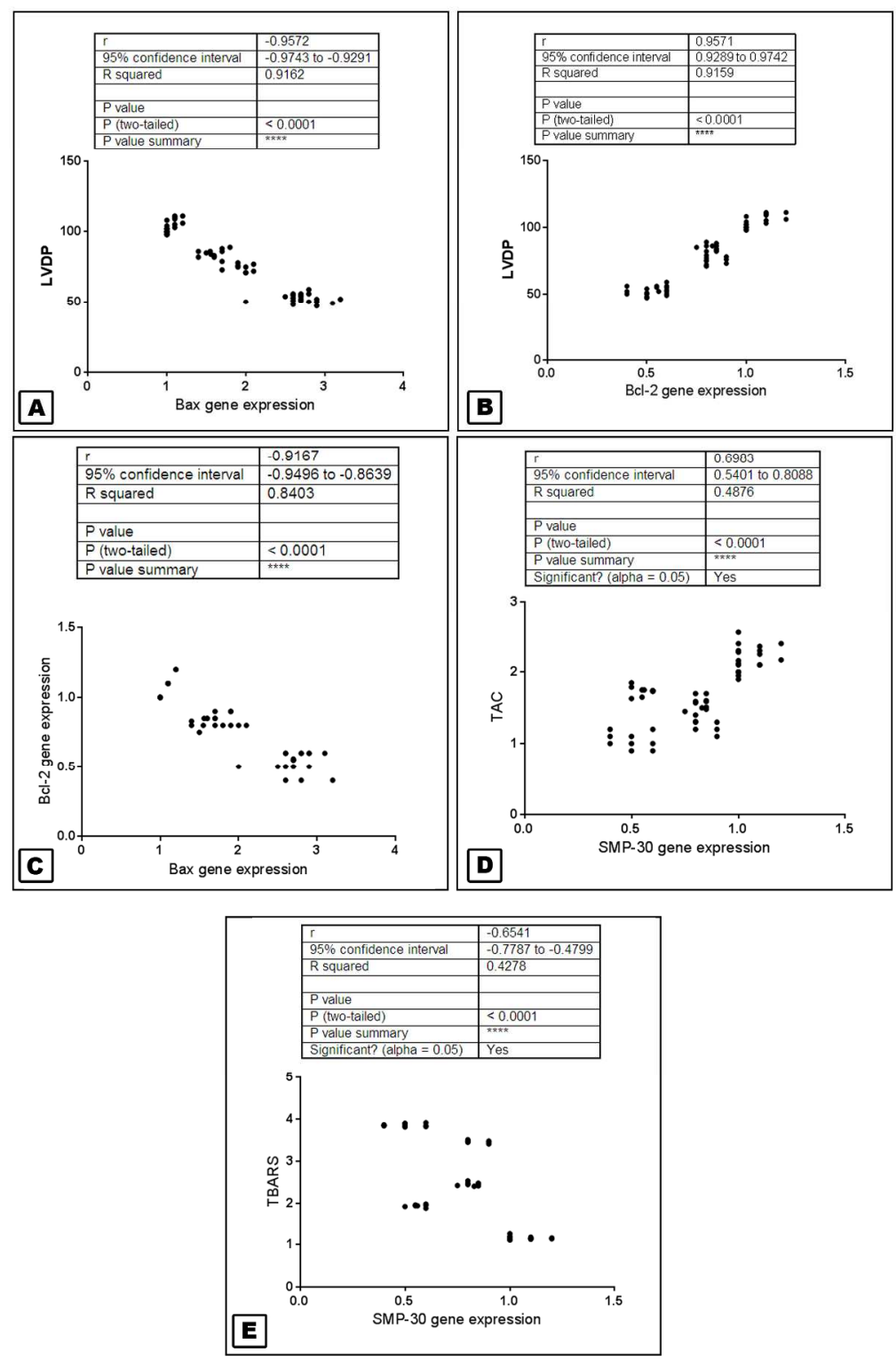

Figure 6.

$199 \times 299 \mathrm{~mm}(300 \times 300 \mathrm{DPI})$ 

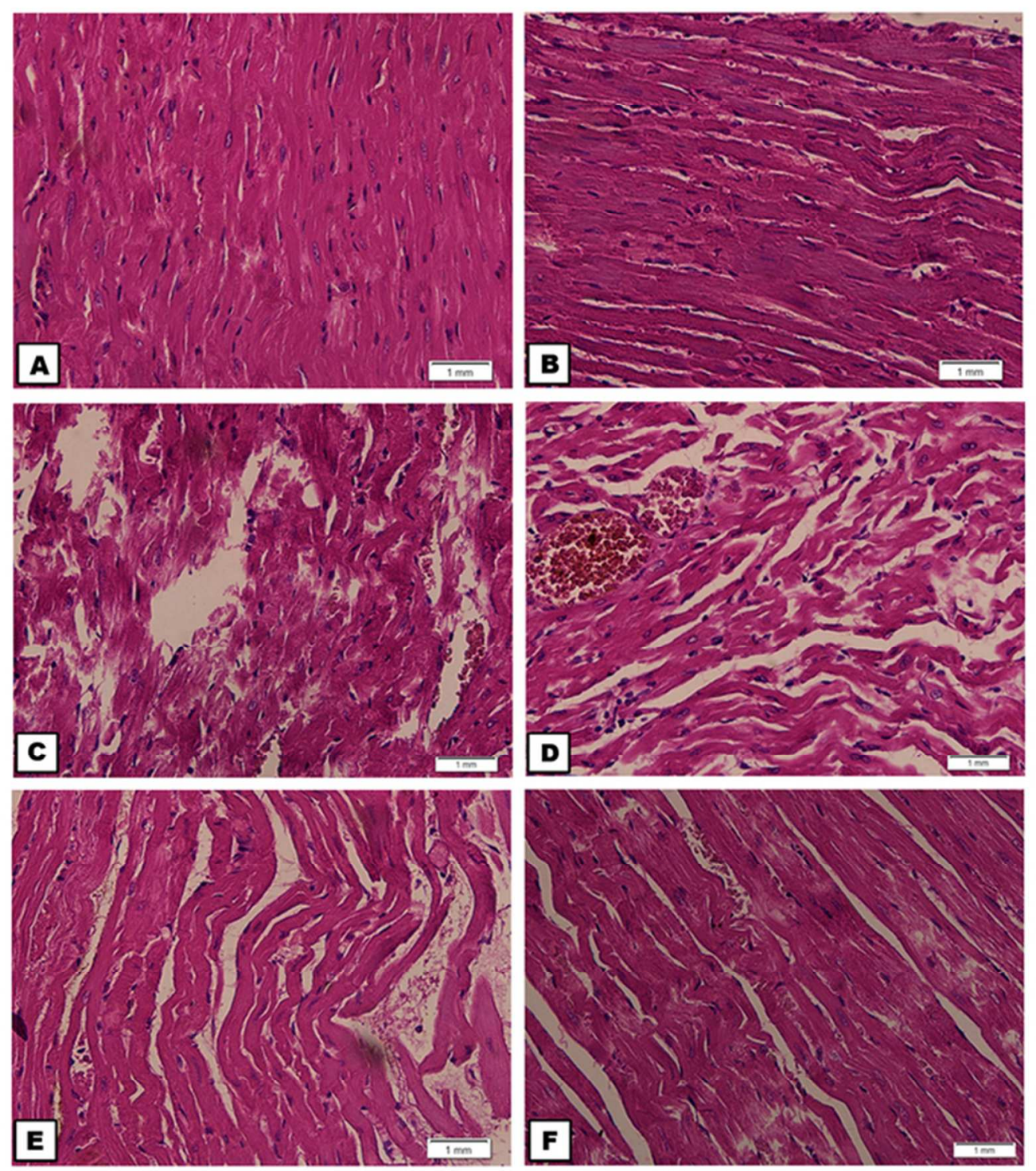

Figure 7.

$57 \times 66 \mathrm{~mm}(300 \times 300$ DPI $)$ 